\title{
Producing synthetic natural gas from microalgae via supercritical water gasification: A techno-economic sensitivity analysis
}

\author{
M. Brandenberger ${ }^{a}$, J. Matzenberger ${ }^{a, 1}$, F. Vogel ${ }^{a}$, Ch. Ludwig ${ }^{a, b, *}$ \\ a Paul Scherrer Institute (PSI), General Energy Research Department (ENE-LBK), CH-5232 Villigen PSI, Switzerland \\ ${ }^{\mathrm{b}}$ École Polytechnique Fédérale de Lausanne (EPFL), School of Architecture, Civil and Environmental Engineering (ENAC-IIE), \\ 1015 Lausanne, Switzerland
}

\section{A R T I C L E I N F O}

Article history:

Received 26 January 2012

Received in revised form

17 June 2012

Accepted 15 December 2012

Available online $\mathrm{xxx}$

Keywords:

Algae

Synthetic natural gas (SNG)

Supercritical water gasification

Sensitivity analysis

Bioenergy

Process economics

\begin{abstract}
A B S T R A C T
A techno-economic sensitivity analysis of the production of synthetic natural gas (SNG) via catalytic supercritical water gasification (SCWG) of microalgae produced in raceway ponds (RP), tubular-, or flat-panel-airlift photobioreactors (FPA-PBR) has been perfomed. The aim of combining microalgae production with SCWG is to close material flows with respect to water and nutrients, the so called SunCHem process. The sensitivity analysis is based on an annual production of $86,500 \mathrm{t}$ of microalgae biomass yielding 1.14 PJ of methane per year. The sensitivity analysis showed that with an annual algae productivity of $38.5 \mathrm{t}$ per hectare of RP an energy return on energy invested (EROEI) of 1.84 can be achieved for the self-sufficient base case scenario. An SNG production cost of $194 € \mathrm{GJ}^{-1}$ was obtained for RP. An EROEI of 0.08 was calculated for tubular PBR with a productivity of $75.1 \mathrm{tha}^{-1} \mathrm{a}^{-1}$ in the base case scenario and thus was found to be inappropriate for SNG production. EROEI for FPA-PBR with an assumed microalgae productivity of $79 \mathrm{t} \mathrm{ha}^{-1} \mathrm{a}^{-1}$ was found to be 1.01 in the base case scenario and an SNG production cost of $266 € \mathrm{GJ}^{-1}$. With significantly more optimistic assumptions concerning microalgae productivity, energy input and capital requirement with respect to microalgae cultivation, an EROEI of 3.6-5.8 and SNG production costs of 53-90€ GJ $J^{-1}$ were found for RP, whereas for FPA-PBR an EROEI of 2-3.7 and SNG production costs of $30-103 € \mathrm{GJ}^{-1}$ were obtained.
\end{abstract}

(c) 2013 Elsevier Ltd. All rights reserved.

\section{Introduction}

The potential of microalgae as a renewable energy source, as a provider of renewable bulk and high value chemicals for the chemical and pharmaceutical industry, as a source of proteins for animal feedstock and fertilizer has made them the subject of considerable research effort in the past [1,2]. However, the economic viability and energy efficiency of biofuels made from microalgae are presently intensively discussed. The main obstacles to large scale introduction of biofuels from microalgae are the high investment costs and energy input required for microalgae cultivation and harvesting $[3,4]$.

\footnotetext{
* Corresponding author. Paul Scherrer Institute, General Energy Research (ENE), Bioenergy and Catalysis Laboratory, CH-5232 Villigen PSI, Switzerland. Tel.: +41 (0)56 310 2696; fax: +41 (0)56 3102199 .

E-mail address: christian.ludwig@psi.ch (Ch. Ludwig).

${ }^{1}$ Current address: Vienna University of Technology, Institute of Power Systems and Energy Economics, Gusshausstrasse 27-29, 1040 Wien, Austria.

0961-9534/\$ - see front matter @ 2013 Elsevier Ltd. All rights reserved.

http://dx.doi.org/10.1016/j.biombioe.2012.12.038
} 
Yet, published data on the environmental sustainability, economic and energetic viability of biofuels from microalgae focused mainly on biodiesel [3-5]. Biomethane (biogas) from microalgae, on the other hand, has been mostly considered as a waste treatment technology for the organic leftovers from the biodiesel production process [6,7]. The economic and energetic potential of converting the entire microalgal biomass into biomethane has not received much attention. This paper considers thus the production of synthetic natural gas (SNG) via catalytic supercritical water gasification (SCWG) of microalgae with closed material flows in terms of water and nutrients, the so called SunCHem process [8,9]. However, due to the immaturity of the technology, there is a significant uncertainty to determine exactly in advance to which extent the different factors can be effectively improved in the future. Consequently, a sensitivity analysis has been performed with an optimistic scenario, where half of the optimization potential is realized and a very optimistic scenario, where the optimization potential is fully exploited, based on the sensitivity analysis parameters.

Catalytic SCWG allows the production of SNG from biomass without prior drying (water content $=50 \%-90 \%$ ) at high chemical energy conversion efficiencies of up to $70 \%-77 \%$ $[10,11]$. Such high energy conversion efficiencies are possible because at supercritical pressure the specific and latent heat demand of water is strongly decreased, thus being a promising biofuel pathway for feedstocks with high water content like microalgae [12]. Furthermore, catalytic supercritical water gasification converts the entire reactive biomass to a product gas, and due to residence times in the order of minutes high biomass conversion rates are possible on a much smaller area than for anaerobic digestion.

In addition, catalytic SCWG allows the potential recovery of nutrients from the microalgal biomass during SNG production. At supercritical water (SCW) conditions, the nutrients precipitate because the fluid exhibits very low solubility for salts. It has been shown that with a reverse flow gravity separator, type 1 and 2 salt mixtures of $\mathrm{NaNO}_{3} / \mathrm{K}_{2} \mathrm{CO}_{3}, \mathrm{~K}_{2} \mathrm{HPO}_{4} /$ $\mathrm{KH}_{2} \mathrm{PO}_{4}, \mathrm{Na}_{2} \mathrm{CO}_{3} / \mathrm{K}_{2} \mathrm{SO}_{4}, \mathrm{Na}_{3} \mathrm{PO}_{4} / \mathrm{K}_{2} \mathrm{SO}_{4}$ and single salt solutions such as $\left(\mathrm{NH}_{4}\right)_{2} \mathrm{CO}_{3}, \mathrm{NH}_{4} \mathrm{Cl}, \mathrm{Ca}\left(\mathrm{NO}_{3}\right)_{2},\left(\mathrm{NH}_{4}\right)_{2} \mathrm{SO}_{4}$ and many more could be separated and recovered from aqueous solutions with efficiencies between $80 \%$ and $97 \%$ [13-15].

The production of chemical fertilizer was singled out by Clarens et al. [3] and Lardon et al. [16] as a main factor concerning the environmental burden of microalgal fuels with respect to their greenhouse gas emissions, human and marine ecosystem toxicity potential as well as for the emission of acidifying substances. Conversion of microalgae to SNG via catalytic SCWG thus could reduce the consumption of nutrients for algae cultivation.

\section{Methodology}

In view of the presently high production costs and energy input for microalgae cultivation and as such for biofuels derived from microalgae, a techno-economic sensitivity analysis has been done for the production of synthetic natural gas (SNG) via catalytic supercritical water gasification (SCWG) of sweet water microalgae based on three different microalgae production systems: Raceway ponds (RP), tubular-, and flatpanel-airlift photobioreactors (FPA-PBR). This work thus gives a range of SNG production costs and energy return on energy invested (EROEI) from microalgae via catalytic SCWG according to different scenarios of technological improvements. A detailed summary of the variables settings, the sensitivity analysis and all assumptions in this model can be found in the Supporting Information (SI) provided in several additional tables and figures. In particular, the SI describes the technological and economic model as well as the performance metrics, including the equations, used in this work. The data is based on published peer-reviewed values, personal communications from manufacturers and what are regarded to be realistically achievable values. EROEI is defined according to equation (2.1). It should be mentioned that the EROEI includes power production from SNG (see SI).

$$
\text { EROEI }=\frac{\text { Usable acquired energy }}{\text { Energy expended }}
$$

Fig. 1 gives an overview of the flowsheet of the combined microalgae cultivation and catalytic SCWG process. It is assumed that the carbon dioxide is provided from a combustion source such as a coal power plant, cement plant, biogas plant with a combined heat and power plant (CHP) or a petrochemical refinery. The dry flue gas is assumed to be composed of $15 \% \mathrm{CO}_{2}$ and $85 \% \mathrm{~N} 2$ [17].

The closed PBR are not actively cooled, as they are cultivated with thermophilic algal species and because we believe that actively cooled PBR's are not suitable for large-scale algae production due to the large amounts of heat, which need to be removed to keep the broth temperature at $298 \mathrm{~K}$ or $308 \mathrm{~K}$ (see SI for more details) [18].

A circular plant layout is assumed for the three different microalgae cultivation systems: Raceway ponds (RP), tubular-, or FPA-PBR with the flue gas source, the SCWG plant and the dewatering units in the center as shown in Fig. SI 1. The RP and PBR are positioned around the center and are organized in modules of 100 ha size. They are connected with the control and processing units via flue gas and water pipes.

\section{Results and discussion}

\subsection{Analysis of energy consumption: base case}

Table 1 shows the results for the base case scenarios calculated on the assumptions given in Table SI 1 - Table SI 3 in the SI. Energy use for flue gas transport is highest for RP; this is not unexpected because the flue gas needs to be transported over the longest distance. For an average transportation distance of $21 \mathrm{~km}$ for the case with $\mathrm{RP}, 113 \mathrm{MJ}$ are required to transport one tonne of $\mathrm{CO}_{2}$ from the source to the cultivation sites and $79-81 \mathrm{MJ} \mathrm{t}^{-1}$ for tubular- and FPA-PBR, respectively. The values obtained are similar to the $80.3 \mathrm{MJ} \mathrm{t}^{-1}$ for a 1000 ha direct $\mathrm{CO}_{2}$ injection system calculated by Kadam [17]. The results show that energy input for flue gas transport is a minor contribution if $\mathrm{CO}_{2}$ is supplied by large diameter low-pressure pipelines (see SI for details).

Energy input to pump the algal slurry to the dewatering location and return the reclaimed water to the cultivation 


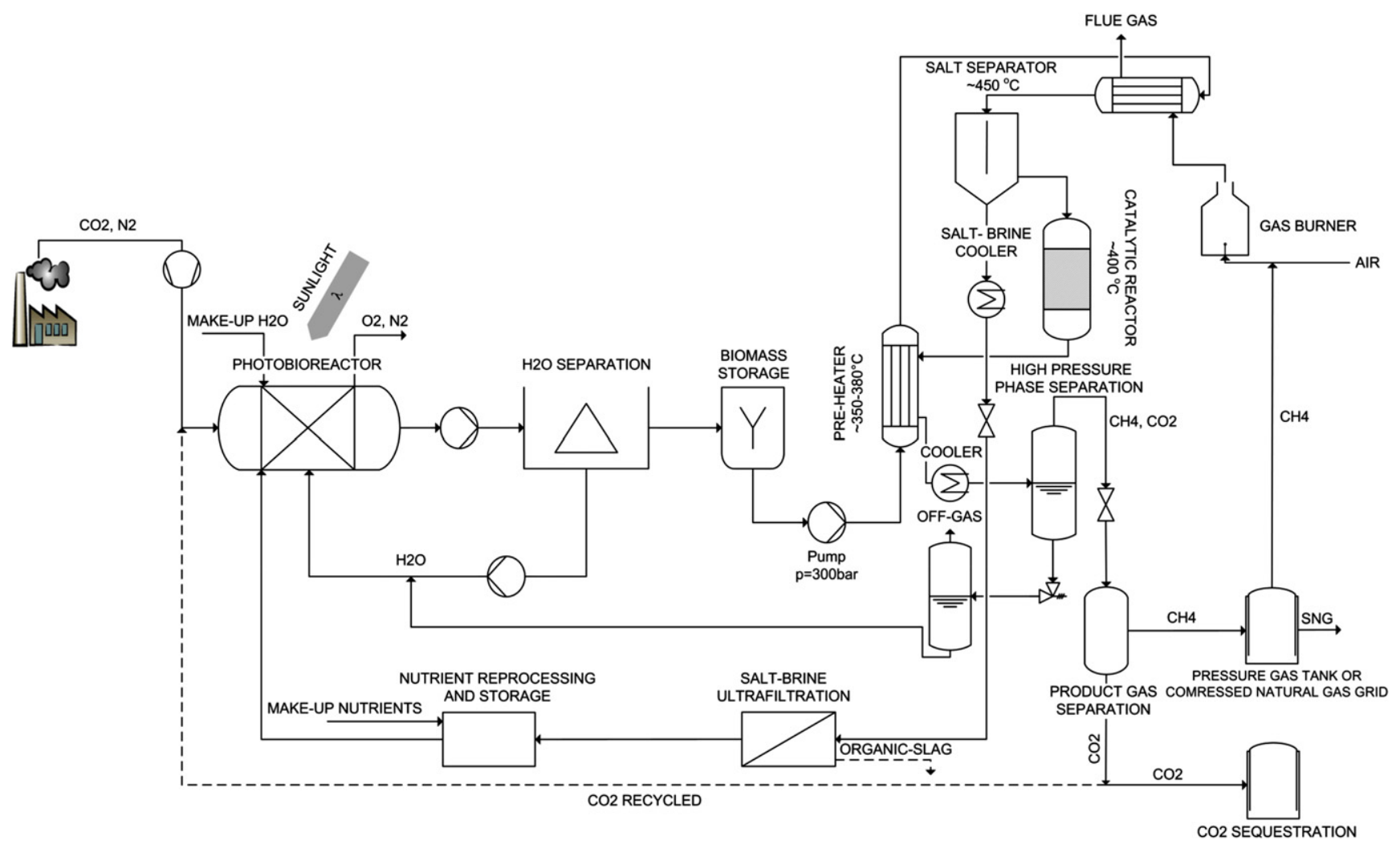

Fig. 1 - Flowchart of the combined microalgae cultivation and catalytic supercritical water gasification process (SunCHem process).

sites shows strong differences between RP, tubular- and FPAPBR. Significantly smaller volumes of algal slurry and reclaimed water need to be transported back and forth between the dewatering and cultivation sites for tubular- and
FPA-PBR (harvesting concentration of 3.6-8 $\mathrm{g} \mathrm{L}^{-1}$ ) than with RP. The energy need for RP is thus 4-6 times higher $\left(7421 \mathrm{GJ} \mathrm{a}^{-1}\right)$ at a biomass harvesting concentration of $0.5 \mathrm{~g} \mathrm{~L}^{-1}$ as shown in Table 1.

\section{Table 1 - Energy return on energy invested (EROEI) for RP, tubular PBR and FPA-PBR.}

\begin{tabular}{|c|c|c|c|c|c|c|}
\hline Process unit & $\mathrm{RP}+\mathrm{SCWG}$ & $\mathrm{RP}+\mathrm{SCWG}$ & $\begin{array}{c}\text { Tubular } \\
\text { PBR + SCWG }\end{array}$ & $\begin{array}{c}\text { Tubular } \\
\text { PBR + SCWG }\end{array}$ & $\begin{array}{c}\text { FPA } \\
\text { PBR }+ \text { SCWG }\end{array}$ & $\begin{array}{c}\text { FPA } \\
\text { PBR }+ \text { SCWG }\end{array}$ \\
\hline $\begin{array}{l}\text { Algae culture and } \\
\text { harvesting }\end{array}$ & TJ $a^{-1}$ & $\%$ & TJ $a^{-1}$ & $\%$ & TJ $a^{-1}$ & $\%$ \\
\hline Flue gas transport & 8.6 & 2.5 & 6.1 & 0.1 & 6.0 & 1.0 \\
\hline $\begin{array}{l}\text { Water circulation } \\
\text { pumps }\end{array}$ & 7.4 & 2.2 & 2.3 & 0.0 & 1.3 & 0.2 \\
\hline Dewatering & 51.3 & 15.1 & 8.0 & 0.1 & 4.6 & 0.7 \\
\hline $\begin{array}{l}\text { Air blowers/paddle } \\
\text { wheels }\end{array}$ & 213 & 62.7 & 7996 & 99.1 & 545 & 88.5 \\
\hline \multicolumn{7}{|l|}{ Algae conversion } \\
\hline Feed pump & 14.1 & 4.2 & 14.1 & 0.2 & 14.1 & 2.3 \\
\hline Gas separation & 44.4 & 13.1 & 44.4 & 0.6 & 44.4 & 7.2 \\
\hline Ultrafiltration & 0.6 & 0.2 & 0.6 & 0.0 & 0.6 & 0.1 \\
\hline \multicolumn{7}{|l|}{ Total energy } \\
\hline $\begin{array}{l}\text { Consumption } \\
\left.\text { (E } E_{\text {required }}\right)\end{array}$ & 339 & 100.0 & 8071 & 100.0 & 616 & 100.0 \\
\hline $\begin{array}{l}\text { Total energy of } \\
\text { biomass }\left(E_{\text {algae }}\right)\end{array}$ & 1895 & & 1895 & & 1895 & \\
\hline Bio-SNG $\left(E_{\mathrm{SNG}}\right)$ & 1135 & & 1135 & & 1135 & \\
\hline Energy efficiency & $\%$ & & $\%$ & & $\%$ & \\
\hline$\eta_{\text {SCWG }}$ & 59.9 & & 59.9 & & 59.9 & \\
\hline EROEI & 1.84 & & 0.08 & & 1.01 & \\
\hline
\end{tabular}

Please cite this article in press as: Brandenberger $\mathrm{M}$, et al., Producing synthetic natural gas from microalgae via supercritical water gasification: A techno-economic sensitivity analysis, Biomass and Bioenergy (2013), http://dx.doi.org/10.1016/ j.biombioe.2012.12.038 
Typically the algal slurry is dewatered to a feed concentration of $20 \%$ total solids (TS) for catalytic SCWG (Table SI 3). In the case of RP, the energy input for dewatering accounts for a large part of the total process energy on the order of $15 \%$ due to the low initial algal biomass concentration. Accordingly, the energy input for dewatering the algal slurry from tubularor FPA-PBR is modest and only accounts for a small fraction of the total process energy.

Power consumption for air blowers and paddle wheels, in order to assure proper mixing of the culture medium and gas transfer, are very low per reactor volume $\left(\mathrm{m}^{3}\right)$ for the RP compared to the two other systems. Nonetheless the large water volume required due to the low volumetric biomass productivity of RP partially offsets the low energy input and thus accounts for $63 \%$ of the total energy consumption of RP. However, as can be seen in Table 1, the energy input for $\mathrm{CO}_{2}$ mass transfer and mixing in tubular and FPA-PBR is significantly higher. In both cases the energy input for $\mathrm{CO}_{2}$ mass transfer and mixing accounts for $89 \%-99 \%$ of the energy required to cultivate the microalgae. Consequently the air blowers are the main reason for the unfavorable EROEI for the closed PBR systems. Especially the large power needs for mixing in tubular PBR of $2500 \mathrm{~W} \mathrm{~m}^{-3}$ (99\% of the total process energy) renders this production system apparently uninteresting for biofuel production [19]. However, recent calculations from Norsker et al. [20] suggest much lower power inputs for tubular PBR on the order of $<100 \mathrm{~W} \mathrm{~m}^{-3}$, which would make this cultivation system a net energy producer.

The energy efficiency for the conversion of algal biomass into methane through catalytic SCWG depends on the TS concentration of the feedstock and on its elemental composition. Because it is assumed in the base case that the algal slurry is dewatered to the same TS concentration and composition for all three cultivation systems, energy input as well as energy output for the catalytic SCWG process are equal. A gross energy efficiency of $59.9 \%$ is obtained for the conversion of algal biomass into SNG (detailed calculations are given in the SI). This value is slightly lower than predicted by state of the art models for SNG production from microalgae by SCWG which can be as high as 70\% [10], hence showing the conservative approach of our model assumptions with respect to catalytic SCWG. The dry product gas composition at $0{ }^{\circ} \mathrm{C}$ and $0.1 \mathrm{MPa}$ after the SCWG reactor consists mainly of $\mathrm{CH}_{4}(51.8 \%)$ and $\mathrm{CO}_{2}(44 \%)$. Some $\mathrm{H}_{2}(4.1 \%)$, traces of $\mathrm{CO}\left(7.810^{-2} \%\right)$ and $\mathrm{C}_{2} \mathrm{H}_{6}\left(31.410^{-4} \%\right)$ are present in the product gas as well. The specific methane yield is calculated to be in the base case $0.35 \mathrm{~kg} \mathrm{~kg}^{-1} \mathrm{TS}$ of algal biomass (see SI).

In summary, the EROEI is $>1$ for the RP and FPA-PBR but highly unfavorable for the tubular PBR (EROEI =0.08). It is necessary to take into account that the energy required to cultivate the microalgae is electric power. Therefore, the EROEI is significantly lower than one would expect from Table 1 if only the energy consumed during the production and conversion of the algal biomass was considered. The EROEI takes in account that all electric power needs to be provided internally, and thus a certain part of the produced SNG is needed for power production. This is in strong contrast to other studies, where additional renewable energy systems, such as wind energy, are proposed in the future for power supply of microalgae cultivation in order to achieve a positive net energy balance [21]. The results in Table 1 show that for the base case, only the combination of RP together with catalytic SCWG of algal biomass allows to obtain a net energy producing process (EROEI $=1.84$ ).

\subsection{Process economics: base case}

The significant differences in energy consumption, production methods and hence capital costs between RP, tubularand FPA-PBR are also apparent when it comes to production costs. Table 2 shows a summary of the associated production costs for the three different base case scenarios, as well as the distribution of production costs in percent (\%).

The specific SNG energy cost are $194 € \mathrm{GJ}^{-1}$ for the RP case, $484 € \mathrm{GJ}^{-1}$ for the tubular PBR and $266 € \mathrm{GJ}^{-1}$ for the FPA-PBR configuration. In contrast, natural gas is sold in Switzerland for a price of $17.3 € \mathrm{GJ}^{-1}$ [22], showing that with the proposed cost structure and the assumptions made in the base case scenarios, SNG production from microalgae is economically highly unfavorable. Nevertheless, the estimated production costs of $1 \mathrm{~kg}$ of dry algal biomass ( $€ \mathrm{~kg}^{-1} \mathrm{TS}$ ) are lower than what present commercial producers are able to produce. van Beilen [4] gives a price range of $5-15 \$ \mathrm{~kg}^{-1} \mathrm{TS}$ algal biomass produced in raceway ponds and mentions likely production costs for algal biomass somewhere between 2500 \$ and 5000 \$ per tonne of algal biomass produced in China. This cost range corresponds quite well with the cost estimation in the base case scenario for the RP with an algal production cost of $2.42 €$ $\mathrm{kg}^{-1}$ TS algal biomass, which is a bit lower than the above mentioned production costs for China. Of course, it has to be taken into account that in the RP scenario, economy of scale is assumed, microalgae are not dried but only dewatered to $20 \%$ TS and nutrients contained in the algal biomass are partially recycled. If compared with other cost estimations our estimations for RP are much higher. Williams and Laurens [1] calculated production costs for large scale algal production of $0.41 \$ \mathrm{~kg}^{-1}$. However, as is shown later, these values can only be achieved for highly optimized cultures. In fact, Williams and Laurens [1] assume an annual production of dry algal biomass of $103 \mathrm{t} \mathrm{ha}^{-1} \mathrm{a}^{-1}$ for a combined PBR - RP system. Such high productivities however, have never been achieved outdoors and need to be confirmed [4].

The production costs for algal biomass by tubular PBR or FPA-PBR in the base case scenarios are about 1.5-3 times higher than with RP. However, the difference is not as large as one would expect from the difference in required capital investment for the culture systems given in Table 2 . Indeed, the investments for dewatering in the case of the RP are substantial with respect to the actual culture system $(27 \%$ of the production costs for the raceway pond scenario compared to $<1.5 \%$ for the PBR scenarios) and the algal biomass productivity is also lower for RP than for closed photobioreactors. This partially offsets the advantage given by the low investment costs for the culture system in the raceway scenario.

The construction costs for the production of SNG are split into the required capital investment for the culture system, for the culture system including dewatering and storage, for the SCWG part and for the entire SunCHem process (all expressed in $€ \mathrm{ha}^{-1}$ ). It becomes evident that the capital investment in the case of both closed photobioreactors 
Table 2 - Process economics (including labor costs): base case.

\begin{tabular}{|c|c|c|c|}
\hline \multirow[t]{2}{*}{ Parameter/process unit } & \multicolumn{3}{|c|}{ Base case } \\
\hline & $\mathrm{RP}+\mathrm{SCWG}$ & $\begin{array}{c}\text { Tubular } \\
\text { PBR + SCWG }\end{array}$ & $\begin{array}{c}\text { FPA- } \\
\text { PBR + SCWG }\end{array}$ \\
\hline Construction costs culture system $\left(€ \mathrm{ha}^{-1}\right)$ & 64,602 & $1,485,846$ & $1,485,846$ \\
\hline $\begin{array}{l}\text { Construction costs culture system incl. } \\
\text { harvesting \& storage }\left(€ \mathrm{ha}^{-1}\right)\end{array}$ & 416,911 & $1,605,414$ & $1,564,837$ \\
\hline Construction costs SCWG $\left(€ \mathrm{ha}^{-1}\right)$ & 14,360 & 28,018 & 29,454 \\
\hline Construction costs SunCHem process $\left(€ \mathrm{ha}^{-1}\right)$ & 442,814 & $1,655,955$ & $1,617,970$ \\
\hline Labor costs $\left(€ \mathrm{ha}^{-1} \mathrm{a}^{-1}\right)$ & 27,342 & 27,342 & 27,342 \\
\hline Total production costs $\left(€ \mathrm{ha}^{-1} \mathrm{a}^{-1}\right)$ & 97,931 & 477,622 & 276,014 \\
\hline Production costs of algal biomass ( $\left.€ \mathrm{~kg}^{-1} \mathrm{TS}\right)$ & 2.42 & 6.24 & 3.38 \\
\hline Production costs SNG $\left(€ \mathrm{GJ}^{-1}\right)$ & 194 & 484 & 266 \\
\hline \multicolumn{4}{|l|}{ Production costs (in \%) } \\
\hline Algae culture and harvesting & $\%$ & $\%$ & $\%$ \\
\hline Flue gas transport & 1.7 & 0.5 & 0.9 \\
\hline Photobioreactors/raceway ponds & 10.5 & 26.9 & 46.8 \\
\hline Dewatering & 26.4 & 1.3 & 1.2 \\
\hline Power for air blowers/paddle wheels & 3.0 & 44.4 & 5.5 \\
\hline Water circulation pumps & 1.5 & 0.3 & 0.4 \\
\hline Biomass storage & 0.03 & 0.01 & 0.02 \\
\hline Catalytic SCWG & $\%$ & $\%$ & $\%$ \\
\hline HP pumps & 0.20 & 0.08 & 0.15 \\
\hline SCWG & 1.9 & 0.8 & 1.4 \\
\hline Gas separation & 1.5 & 0.6 & 1.1 \\
\hline Ultrafiltration & 0.05 & 0.02 & 0.03 \\
\hline Overheads/labor & $\%$ & $\%$ & $\%$ \\
\hline Maintenance & 16.3 & 12.5 & 21.1 \\
\hline Plant overheads & 9.0 & 6.9 & 11.6 \\
\hline Labor & 18.0 & 3.7 & 6.4 \\
\hline Overheads labor & 9.9 & 2.0 & 3.5 \\
\hline
\end{tabular}

scenarios as well as for the RP are essentially composed of the biomass production part, whereas the actual fraction of capital investment for the catalytic SCWG of the algal biomass is very small. These results show that the economic bottleneck clearly comes from the algal biomass production part, as more than $94 \%$ of the required investment goes into the biomass production for all three scenarios.

\subsection{Base case: sensitivity analysis}

\subsubsection{Energy sensitivity analysis}

The parameters studied in this work and the ranges of variation are given in Table SI 6 in the SI. The tubular PBR was not further investigated because it became obvious during the analysis of the base case that this system is inefficient with respect to net energy production and thus not suitable for SNG production from microalgae with the present assumptions.

Figs. 2 and 3 show the results from the sensitivity analysis of the two remaining viable options with respect to the EROEI: RP and FPA-PBR. The intercept of all lines corresponds to the base case, and any point away from the intercept represents an increase or decrease of EROEI. The steeper the slope of the curve, the higher the EROEI sensitivity towards the parameter.

As can be seen in Figs. 2 and 3, both systems are quite sensitive to the following parameters: air blowers, biomass productivity and SCWG feed concentration. In contrast, the amount of $\mathrm{CO}_{2}$ converted to algal biomass $\left(\mathrm{CO}_{2}\right.$ uptake), has almost no impact. Indeed, whether $25 \%$ (base case $\pm 0 \%$ ) or $90 \%(+360 \%)$ of the emitted $\mathrm{CO}_{2}$ in the flue gas is converted to biomass is irrelevant as there is no energetic penalty for increasing the cultivation area. About $100 \mathrm{~km}^{2}$ of cultivation area are required near a $\mathrm{CO}_{2}$ source for such a scenario where $90 \%$ of the emitted $\mathrm{CO}_{2}$ is converted into biomass (producing $>310,000 \mathrm{t}$ of algal biomass per year), which may represent a significant limiting factor for such an installation.

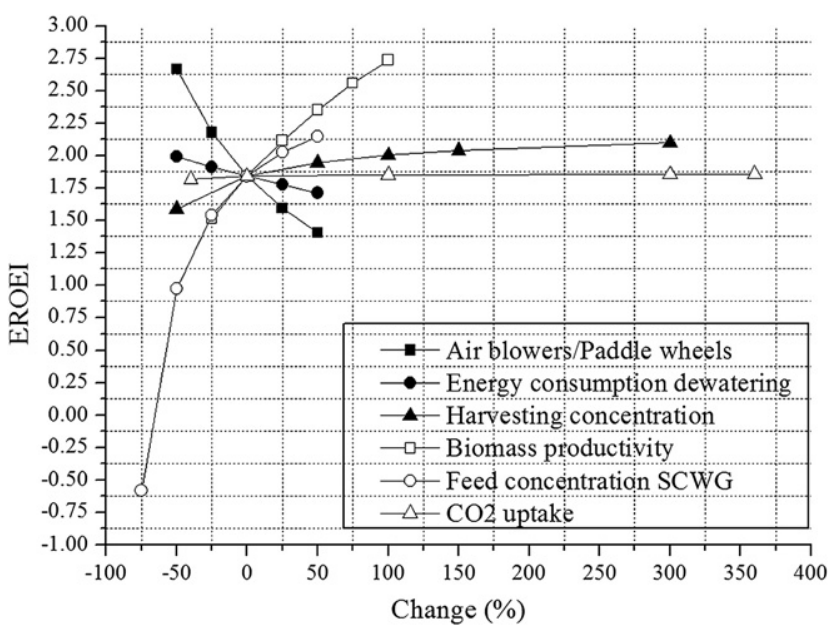

Fig. 2 - Sensitivity analysis RP scenario: EROEI. Sensitivity parameters are shown in the legend.

Please cite this article in press as: Brandenberger $\mathrm{M}$, et al., Producing synthetic natural gas from microalgae via supercritical water gasification: A techno-economic sensitivity analysis, Biomass and Bioenergy (2013), http://dx.doi.org/10.1016/ j.biombioe.2012.12.038 


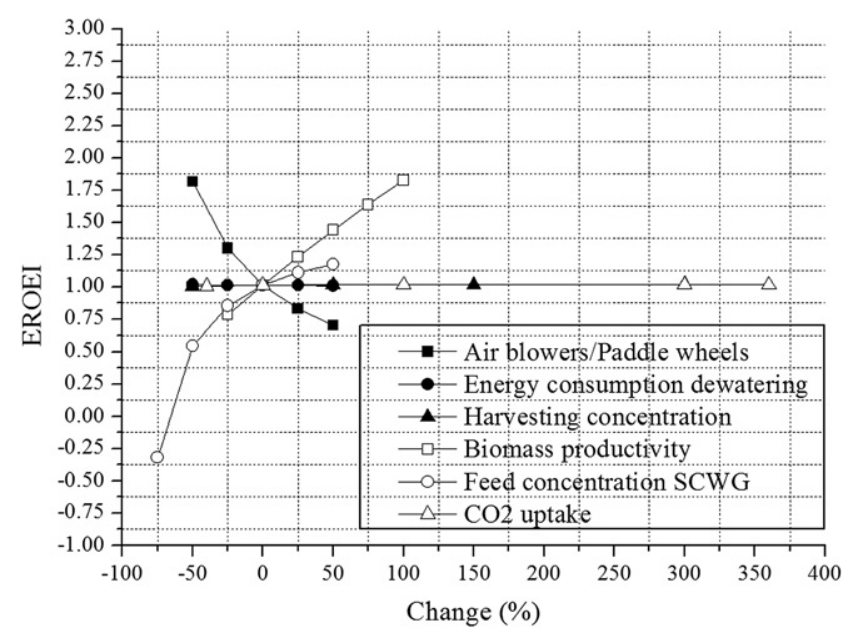

Fig. 3 - Sensitivity analysis FPA-PBR scenario: EROEI. Sensitivity parameters are shown in the legend.

Present research efforts in microalgae cultivation are directed towards lowering energy input and increasing the productivity at the highest harvesting concentration possible [21]. However, it needs to be taken into account that an increase of biomass productivity by $50 \%$ or even by $100 \%$ would mean an annual production of 58-77 $\mathrm{t} \mathrm{ha}^{-1} \mathrm{a}^{-1}$ for RP and 119-158 tha ${ }^{-1} \mathrm{a}^{-1}$ for FPA-PBR. Consequently this would correspond to a photosynthetic efficiency between $2.6 \%$ and $3.5 \%$ for RP and $5.4 \%-7.2 \%$ for FPA-PBR (based on $5040 \mathrm{MJ} \mathrm{m}^{2} \mathrm{a}^{-1}$ solar irradiance for Switzerland) which is close to the maximum theoretical amount of $9 \%$ of the incoming solar irradiation that can be converted into algal biomass [23]. Such high productivities have never been reached in yearround outdoor cultivations, but only under laboratory conditions. From an energetic point of view, it would therefore be easier to focus on lowering the energy input for microalgae cultivation instead of increasing the productivity as both parameters improve the EROEI by a similar level.

With an energy input of $0.29 \mathrm{MJ}$ per cubic meter of algal slurry processed for the belt filters and $3.6 \mathrm{MJ} \mathrm{m}^{-3}$ for the centrifuge (Table SI 1), the energy input for dewatering $1 \mathrm{~kg}$ of algal biomass to $20 \%$ TS is as low as $0.59 \mathrm{MJ} \mathrm{kg}^{-1}$ for RP and $0.15 \mathrm{MJ} \mathrm{kg}^{-1}$ for FPA-PBR, assuming $100 \%$ biomass recovery. As the belt filters preconcentrate the algal slurry to a concentration of $9.5 \%$ TS for the centrifuge, the difference in energy input to recover $1 \mathrm{~kg}$ TS of microalgae, is due to the belt filters. Indeed, this explains the small impact of the energy input for dewatering or the harvesting concentration if they are continuously varied in the sensitivity analysis, the base value being $0.29 \mathrm{MJ} \mathrm{m}^{-3}$ of processed algal slurry for the belt filters. Lardon et al. [16] assumed an electricity input of $1.44 \mathrm{MJ} \mathrm{kg}^{-1}$ microalgae for belt filters which is 2.5 times higher than the values proposed by Mohn [24]. A more conservative assumption for the energy consumption for the belt filters would thus strongly affect the EROEI of the overall process. For example, a similar electricity input for the belt filters as proposed by Lardon et al. [16] would reduce the EROEI for the RP base case by $18 \%$ to 1.51 .

It is energetically favorable to dewater the incoming algal slurry as much as possible before the gasification step as shown in Figs. 2 and 3. Low feed concentrations for the SCWG plant, for example $5 \%$ TS (-75\%), means saving energy during the dewatering step, but consequently mostly water is pumped through the SCWG plant and heated up to supercritical water conditions, instead of biomass. As this step requires much more energy than can be saved during the dewatering step, the EROEI in both cases drops quickly below one. Thus, it should be the aim to dewater the algal slurry up to $30 \%$ TS, as long as the resulting algal slurry remains pumpable.

\subsubsection{Production costs sensitivity analysis}

Table SI 7 in the SI shows the parameters used for the economic sensitivity analysis to calculate the price of one energy unit of SNG expressed in Euro per Gigajoule $\left(€ G J^{-1}\right)$. The intervals were chosen in such a way to reflect possible future improvements. Especially the large decrease in construction costs up to $-90 \%$ shall take into account future cost reductions. This value corresponds to construction costs of only $230,000 € \mathrm{ha}^{-1}$ for a fully installed PBR unit (including harvesting and storage), whereas in the base case the costs are 7 times higher for 1 ha of land covered with PBR.

Fig. 4 shows the results of the sensitivity analysis for the RP. The parameters with the highest saving potential are the harvesting concentration of the algal biomass, the concentration of the feed into the SCWG plant after the dewatering and the biomass productivity. The effect of harvesting at high biomass concentrations allows reducing significantly the investment costs for the dewatering equipment. However, the effect levels off at $128 € \mathrm{GJ}^{-1}$, and a harvesting concentration of $>2 \mathrm{gL}^{-1}$ in $\mathrm{RP}$ will not reduce further the dewatering costs significantly. If only the costs for dewatering are considered, the costs to obtain $1 \mathrm{~kg}$ of dry algal biomass by dewatering the wet algal slurry decreases from $0.67 € \mathrm{~kg}^{-1}$ TS to $0.17 € \mathrm{~kg}^{-1}$ TS (without considering labor and maintenance). This result points to the necessity of cultivating microalgae in such a way that they can be harvested easily, for example, by cultivating microalgae species with a natural tendency to float, or focusing on macroalgae instead of microalgae. An increase of productivity is not

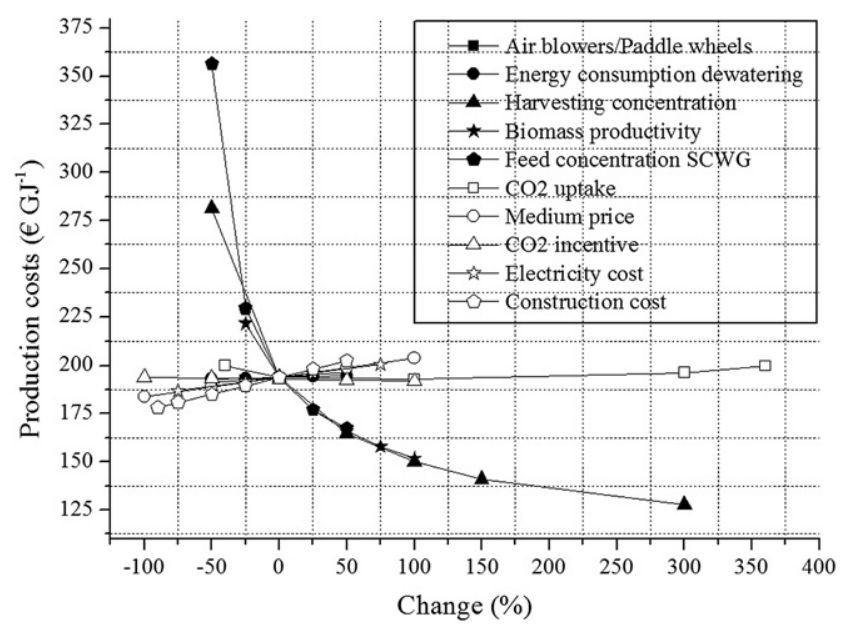

Fig. 4 - Sensitivity analysis RP scenario: SNG production costs $\left(€ \mathrm{GJ}^{-1}\right)$. Sensitivity parameters are shown in the legend. Negative production costs are not shown in the graph as they indicate an EROEI $<1$ of the SunCHem process and thus are meaningless. 
required under such conditions. However, flocculation is not considered as a viable long term option for the SunCHem process. For instance, the need of large amounts of chemicals does not fit into the closed loop aspect of the SunCHem process, where all materials shall be as much as possible recycled.

Dewatering the harvested biomass to a slurry with $30 \%$ TS of algal biomass instead of $20 \%$ TS reduces the production costs to $167 € \mathrm{GJ}^{-1}$ instead of $194 € \mathrm{GJ}^{-1}$, i.e. a reduction by $-14 \%$. This further increase of the dry matter content by $50 \%$ for the hydrothermal gasification step is probably the most easy to achieve.

If the productivity of RP can be increased by $100 \%$ to $77 \mathrm{t} \mathrm{ha}^{-1} \mathrm{a}^{-1}$, a $22 \%$ reduction in production costs compared to the base case may be achieved $\left(152 € \mathrm{GJ}^{-1}\right)$. This is due to the effect that a smaller production surface is required in order to achieve the same annual biomass productivity and thus smaller investment costs for the RP are necessary. Furthermore, labor costs decrease as well because a smaller surface has to be maintained. However, it clearly needs to be stated that such a high productivity in RP, due to poor mixing of the microalgae and the light exposure regime, is questionable and has to the authors' knowledge not yet been shown for year-round outdoor cultivation [4].

The production costs only show little sensitivity towards the remaining parameters. Interestingly, whether the nutrients $\mathrm{N}$ and $\mathrm{P}$ are free (would correspond to $100 \%$ nutrient recycling efficiency from the SCWG process) or a carbon tax of $36 €$ per tonne of $\mathrm{CO}_{2}$ can be generated by displacing fossil natural gas, the SNG production costs are not significantly lowered. Nevertheless, it must not be forgotten that recycling nutrients strongly reduces the environmental impact of the SunCHem process [3].

FPA-PBR show a different cost structure compared to the $\mathrm{RP}$, as shown in Fig. 5. Even though the biomass productivity as well as the dry matter content of the algal slurry fed into the SCWG plant plays an important role, clearly the most sensitive parameter with respect to production costs is the high investment cost for FPA-PBR. A reduction of $90 \%$ in construction costs for fully installed PBR $\left(230,000 € \mathrm{ha}^{-1}\right)$ leads to a decrease in production cost of $66 \%$ and to a production cost of $91 € \mathrm{GJ}^{-1}$. However, such a reduction in construction costs is challenging. Accordingly to a recent study, construction costs of $800,000 € \mathrm{ha}^{-1}$ were proposed for an FPA-PBR (including harvesting and storage of biomass) [25].

\subsection{Economic and energetic optimization potential}

The economic sensitivity analysis presented in the previous section showed that even large improvements of one single parameter with respect to algal biomass production, SCWG and construction costs are not sufficient to obtain an economic process with a positive energy balance. The lowest SNG production costs obtained in the sensitivity analysis by changing one parameter were $128 € \mathrm{GJ}^{-1}$ for the RP and $91 €$ $\mathrm{GJ}^{-1}$ for the FPA-PBR. This is still 4-7 times higher than the targeted renewable energy price of $20 € \mathrm{GJ}^{-1}$ [26]. Moreover, the highest EROEI for RP was 2.7 and 1.8 for FPA-PBR by doubling the biomass productivity. In short, EROEI and production costs can be improved significantly further by improving multiple parameters simultaneously.

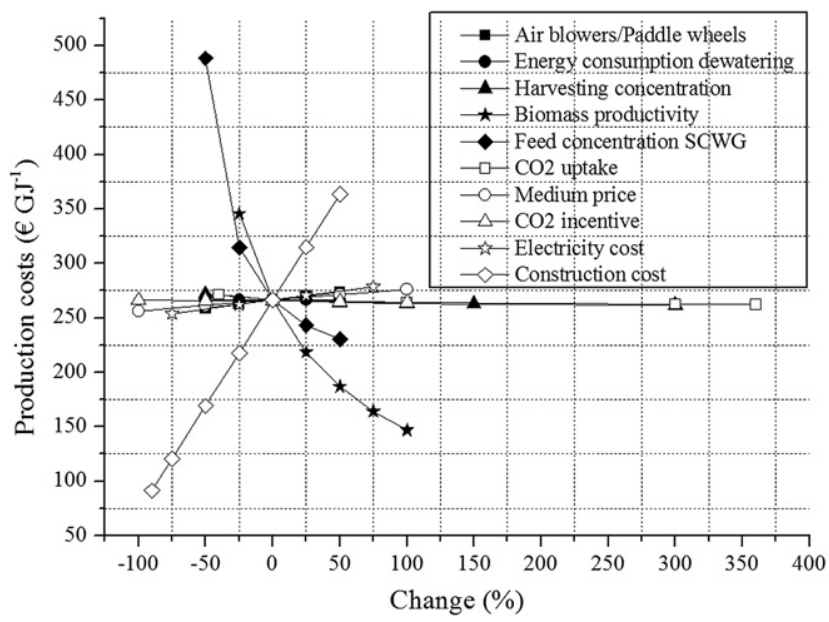

Fig. 5 - Sensitivity analysis FPA-PBR scenario: SNG production costs $\left(€ G^{-1}\right)$. Sensitivity parameters are shown in the legend. Negative production costs are not shown in the graph as they indicate an EROEI $<1$ of the SunCHem process and thus are meaningless.

Fig. 6 shows the results from the assumed scenarios for the $\mathrm{RP}$ and FPA-PBR, with respect to EROEI. Both scenarios indicate that there is potential for a significant further improvement of the EROEI up to 5.8 (RP) and 3.7 (FPA-PBR). Jorquera et al. [27] found a net energy ratio (NER) of 2.56 (RP) and 1.58 (FPA-PBR) for algal oil production, taking into account also the energy required for the manufacturing process of building materials for RP and PBR construction. However, downstream processing of biomass and power production was not considered in NER calculation. In short, NER for total biomass found by Jorquera et al. [27] (NER: $R P=7.01$ and FPA$\mathrm{PBR}=4.33$ ) is slightly higher than the EROEI values for SNG production found in the very optimistic scenario (see Fig. 6), but the EROEI values for the SNG pathway are considerably higher than the one obtained for the oil production pathway, showing that SNG production from microalgae has the potential to be more efficient than the oil production pathway.

Production costs for the optimistic scenario for RP, as shown in Fig. 7, are $90 € \mathrm{GJ}^{-1}$ which is significantly higher than the target value of $20 € \mathrm{GJ}^{-1}$ [26]. Indeed, even the very

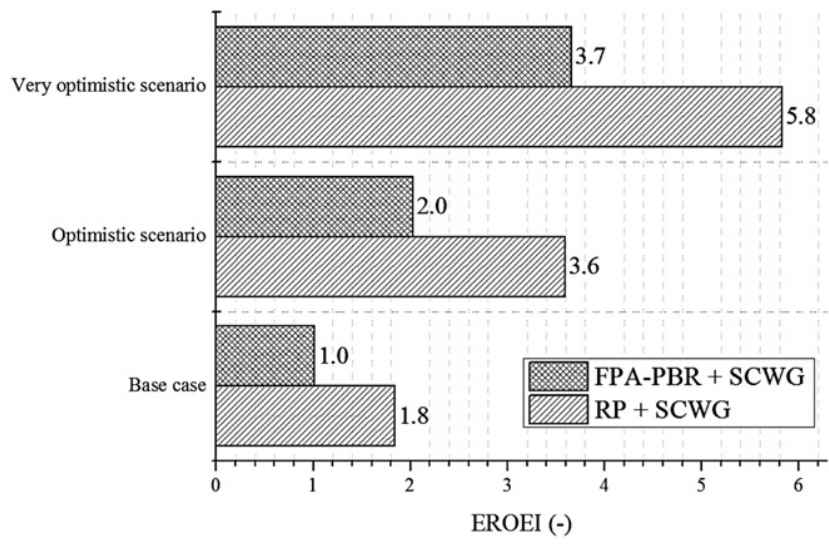

Fig. 6 - Optimization scenarios EROEI for RP and FPA-PBR. 
optimistic scenario would only divide the production costs by less than two $\left(53 € \mathrm{GJ}^{-1}\right)$ and thus still be significantly higher than present energy prices.

Surprisingly, the production costs obtained in the very optimistic scenario for the FPA-PBR are the lowest of all scenarios with only specific production costs of $30 € \mathrm{GJ}^{-1}$ and thus reversed the trend shown in all other scenarios. This behavior is due to two reasons: raceway ponds, due to their lower biomass productivity, require a larger surface area for cultivation than FPA-PBR and therefore implicitly also need more personnel, based on the assumption that 7 persons are required for engineering and maintenance per 100 ha [25]. The labor costs thus are almost twice as big in the case of the very optimistic scenario for RP compared to the FPA-PBR and account for $43 \%$ of the total production costs (see Table SI 5). Clearly, labor costs need to be taken into account, as they make up $30-45 \%$ of the production costs in the case of the raceway ponds and $10-40 \%$ for the FPA-PBR, depending on the scenario. Therefore, not only higher productivities or reduced material costs play a role, but also the automation of the algal production is very important and needs to be considered in the future, something that has largely been overlooked up to now. Alternatively, locations for algal biomass production with low labor costs need to be considered.

The second reason is due to the limited harvesting concentration of $2 \mathrm{~g} \mathrm{~L}^{-1}$ for $\mathrm{RP}$, which means high investment costs for dewatering equipment.

Interestingly, up to this point, the production costs related to the SCWG plant played only a marginal role. For example, the contribution to the production costs was in the base case 3.7\% for RP and 2.7\% for FPA-PBR (see Table SI 5). This is not anymore the case in the very optimistic scenario, where $14.6 \%$ of the production costs are due to the SCWG plant for FPA-PBR and $8.4 \%$ for RP (including gas upgrading).

Finally, a large number of claims concerning microalgae and biofuel production costs have been made over the last years by some algal biofuel start-up companies. Interestingly, most of the claims concerning the very low production costs could not be reconstructed in this work as well as in other publications $[1,2,4,28]$. Some of these reports [29-31] give no details on the assumed labor costs behind their calculations.

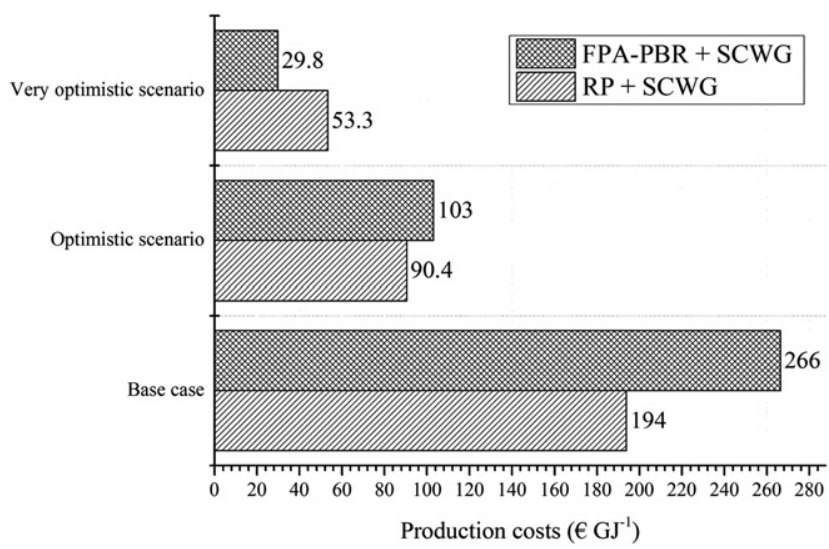

Fig. 7 - Optimization scenarios production costs for RP and FPA-PBR.
Holtermann et al. [31] assumed maintenance and operating costs based on $2 \%$ of the investment sum, which is about 7-9 times lower than what was obtained in this work under any scenario. The separately estimated maintenance and labor costs and plant overheads are shown in Table SI 4. These values are based on the estimations from Norsker et al. and Grima et al. $[25,28]$ and lead to the significantly higher operation and maintenance costs which were used in this study. Another misleading assumption is the actual obtained outdoor biomass productivity, which in some cases are unrealistically high. Unfortunately it is not possible to verify these data published from start-up companies due to their nondisclosure policy. Whether the data are obtained from outdoor culture experiments or simply inaccurate extrapolations of literature data or from laboratory experiments remains unanswered.

\section{Conclusions}

The present work showed that the economical and energetic bottleneck for the production of SNG from algal biomass is not the actual conversion of the wet biomass by catalytic hydrothermal gasification, but the necessity to grow microalgae in artificial culture systems (RP or PBR). More than $95 \%$ of the required investment costs and between 40 and $55 \%$ of the production costs are related to the algal biomass production in the base case scenarios. Under very optimistic assumptions with respect to algal biomass production in the case of the RP and FPA-PBR scenarios more than $70 \%$ of the investment costs and about $26 \%$ of the production costs are due to the algal biomass production part.

However, the assumed investment costs as well as the algal productivities are not easily achievable, and involve a complete change in algal biomass production technology, including novel harvesting technologies, novel reactor materials and designs and algal species with a high productivity as well as a natural tendency to agglomerate rather than to produce high lipid contents. Nevertheless, the calculated production costs are still too high compared with the present price for natural gas.

\section{Acknowledgments}

The authors gratefully acknowledge P. Ripplinger and U. Schmid-Staiger from Subitec for providing data. We thank M. Janssen, M. Schubert, M. Rüdisüli, N. Prasianakis, A. Wokaun and A. Haiduc for valuable discussions. This project was made possible through financial support from the Velux Foundation, Zürich (project Nr. 405), the Competence Center Energy and Mobility (CCEM) and swisselectric research in the frame of the SunCHem project.

\section{Appendix A. Supplementary data}

Supplementary data related to this article can be found at http://dx.doi.org/10.1016/j.biombioe.2012.12.038. 
[1] Williams PJB, Laurens LML. Microalgae as biodiesel \& biomass feedstocks: review \& analysis of the biochemistry, energetics \& economics. Energ Environ Sci 2010;3(5):554-90.

[2] Sheehan J, Dunahay T, Benemann J, Roessler P. A look back at the U.S. Department of Energy's Aquatic Species ProgramBiodiesel from Algae: Close-out Report. Golden CO: National Renewable Energy Laboratory; 1998 July. p. 328 Report No.: NREL/TP-580-24190.

[3] Clarens AF, Resurreccion EP, White MA, Colosi LM. Environmental life cycle comparison of algae to other bioenergy feedstocks. Environ Sci Technol 2010 Mar;44(5): 1813-9.

[4] van Beilen JB. Why microalgal biofuels won't save the internal combustion machine. Biofuel Bioprod Bior 2010;4(1): 41-52.

[5] Murphy CF, Allen DT. Energy-water Nexus for mass cultivation of algae. Environ Sci Technol 2011 Jun;45(13): 5861-8.

[6] Sialve B, Bernet N, Bernard O. Anaerobic digestion of microalgae as a necessary step to make microalgal biodiesel sustainable. Biotechnol Adv 2009;27(4):409-16.

[7] Harun R, Davidson M, Doyle M, Gopiraj R, Danquah M, Forde G. Technoeconomic analysis of an integrated microalgae photobioreactor, biodiesel and biogas production facility. Biomass Bioenerg 2011 Jan;35(1):741-7.

[8] Haiduc AG, Brandenberger M, Suquet S, Vogel F, BernierLatmani R, Ludwig C. SunCHem: an integrated process for the hydrothermal production of methane from microalgae and $\mathrm{CO}_{2}$ mitigation. J Appl Phycol 2009;21(5):529-41.

[9] Stucki S, Vogel F, Ludwig C, Haiduc AG, Brandenberger M. Catalytic gasification of algae in supercritical water for biofuel production and carbon capture. Energy Environ Sci 2009;2(5):535-41.

[10] Gassner M, Vogel F, Heyen G, Marechal F. Optimal process design for the polygeneration of SNG, power and heat by hydrothermal gasification of waste biomass: process optimisation for selected substrates. Energy Environ Sci 2011; 4(5):1742-58.

[11] Gassner M, Vogel F, Heyen G, Marechal F. Optimal process design for the polygeneration of SNG, power and heat by hydrothermal gasification of waste biomass: thermoeconomic process modelling and integration. Energy Environ Sci 2011;4(5):1726-41.

[12] Vogel F. Catalytic Conversion of high-moisture biomass to synthetic natural gas in supercritical water. In: Crabtree RH, editor. Handbook of green chemistry. Heterogenous catalysis, vol. 2. Weinheim: WILEY-VCH Verlag GmbH \& Co. KGaA, ISBN 978-3-527-32497-2; 2009. p. 281-324.

[13] Schubert M, Regler JW, Vogel F. Continuous salt precipitation and separation from supercritical water. Part 1: Type 1 salts. J Supercrit Fluids 2010;52(1):99-112.

[14] Schubert M, Regler JW, Vogel F. Continuous salt precipitation and separation from supercritical water. Part 2: Type 2 salts and mixtures of two salts. J Supercrit Fluids 2010;52(1): 113-24.
[15] Schubert M, Aubert J, Müller JB, Vogel F. Continuous salt precipitation and separation from supercritical water. Part 3: interesting effects in processing type 2 salt mixtures. J Supercrit Fluids 2012;61(1):44-54.

[16] Lardon L, Hélias A, Sialve B, Steyer JP, Bernard O. Life-cycle assessment of biodiesel production from microalgae. Environ Sci Technol 2009 Sep;43(17):6475-81.

[17] Kadam KL. Microalgae production from power plant flue gas: environmental implications on a life cycle basis. Golden CO: National Renewable Energy Laboratory; 2001 June. p. 55 Report No.: NREL/TP-510-29417.

[18] Béchet Q, Shilton A, Fringer OB, Muñoz R, Guieysse B. Mechanistic modeling of broth temperature in outdoor photobioreactors. Environ Sci Technol 2010 Mar;44(6): 2197-203.

[19] Sierra E, Acién FG, Fernández JM, Garcia JL, González C, Molina E. Characterization of a flat plate photobioreactor for the production of microalgae. Chem Eng J 2008 May;138(1-3): 136-47.

[20] Norsker NH, Barbosa MJ, Vermuë MH, Wijffels RH. Microalgal production - a close look at the economics. Biotechnol Adv 2011;29(1):24-7.

[21] Stephens E, Ross IL, Mussgnug JH, Wagner LD, Borowitzka MA, Posten C, et al. Future prospects of microalgal biofuel production systems. Trends Plant Sci 2010 Oct;15(10):554-64.

[22] Kostenvergleich verschiedener Heizsysteme. Verband der Schweizerischen Gasindustrie (VSG) [cited 2011 Sep 13]. Available from: http://www.erdgas.ch/fileadmin/customer/ erdgasch/Data/Erdgas/Preise/kostenvergleich_d.pdf; 2011.

[23] Wijffels RH. Potential of sponges and microalgae for marine biotechnology. Trends Biotechnol 2008 Jan;26(1):26-31.

[24] Mohn FH. Harvesting of micro-algal biomass. In: Borowitzka MA, Borowitzka LJ, editors. Micro-algal biotechnology. Cambridge GB: Cambridge University Press; 1988. p. 395-414.

[25] Norsker NH, Barbosa MJ, Vermuë MH, Wijffels RH. Microalgal production - a close look at the economics. Biotechnol Adv 2011;29(1):S11. Suppl Design Basis.

[26] Schmitz N, Henke J, Klepper G. Biokraftstoffe: Eine vergleichende Analyse. Gülzow DE: Fachagentur Nachwachsende Rohstoffe e.V.; 2009. p. 85 Report FNR 2009.

[27] Jorquera O, Kiperstok A, Sales EA, Embiruçu M, Ghirardi ML. Comparative energy life-cycle analyses of microalgal biomass production in open ponds and photobioreactors. Bioresour Technol 2010 Feb;101(4):1406-13.

[28] Grima EM, Belarbi EH, Fernandez FGA, Medina AR, Chisti Y. Recovery of microalgal biomass and metabolites: process options and economics. Biotechnol Adv 2003 Jan;20(7-8): 491-515.

[29] Chisti Y. Biodiesel from microalgae. Biotechnol Adv 2007 May;25(3):294-306.

[30] Schenk P, Thomas-Hall S, Stephens E, Marx U, Mussgnug J, Posten C, et al. Second generation biofuels: high-efficiency microalgae for biodiesel production, paper 1. Bioenerg Res 2008;1:20-43.

[31] Holtermann T, Madlener R. Assessment of the technological development and economic potential of photobioreactors. Appl Energy 2011 May;88(5):1906-19. 